\title{
Thermochemical Investigations of Associated Solutions: 4. Calculation of Carbazole-Dibutyl Ether Association Constants from Measured Solubility in Binary Solvent Mixtures
}

\begin{abstract}
James W. McCargar and William E. Acree, JR. ${ }^{x}$ Accepted for publication April 21, 1987.

Abstract $\square$ Experimental solubilities are reported for anthracene and carbazole in binary dibutyl ether plus $n$-hexadecane and dibutyl ether plus squalane solvent mixtures at $25^{\circ} \mathrm{C}$. Results of these measurements, used in conjunction with the extended nearly ideal binary solvent (NIBS) model, enabled calculation of the carbazole-dibutyl ether association constant. The numerical value obtained was independent of the hydrocarbon cosolvent, and compared favorably with previously reported values based on carbazole solubilities in solvent mixtures containing much smaller alkane cosolvents.
\end{abstract}

Received February 9, 1987, from the Department of Chemistry, Kent State University, Kent, $\mathrm{OH} 44242$.

This work continues ${ }^{1-13}$ a systematic search for mixing models and equations which will provide predictions for thermochemical properties of a solute at high dilution in binary solvent mixtures. In an earlier paper, Acree et al. ${ }^{8}$ extended the basic nearly ideal binary solvent (NIBS) model to systems containing association between the solute (component A) and a complexing cosolvent (component C).

$$
\begin{aligned}
& \mathrm{A}_{1}+\mathrm{C}_{1} \rightleftharpoons \mathrm{AC} \\
& K_{\mathrm{AC}}^{\phi}=\frac{\phi_{\mathrm{AC}}}{\phi_{\mathrm{A}_{1}} \phi_{\mathrm{C}_{1}}}
\end{aligned}
$$

A relatively simple expression was developed for the determination of solute-solvent equilibrium constants from the measured solubility as a function of solvent composition and the excess Gibbs free energy of the binary solvent mixture.

$$
\begin{gathered}
R T\left[\ln \left(\mathrm{a}_{\mathrm{A}}^{\text {solid }} / \phi_{\mathrm{A}_{1}}^{\mathrm{sat}}\right)-1+\bar{V}_{\mathrm{A}}\left(\frac{\phi_{\mathrm{A}_{1}}^{\mathrm{sat}}}{\bar{V}_{\mathrm{A}}}+\frac{\phi_{\mathrm{B}}}{\bar{V}_{\mathrm{B}}}+\frac{\phi_{\mathrm{C}}}{\bar{V}_{\mathrm{C}}}\right)\right]= \\
\left(1-\phi_{\mathrm{A}}^{\mathrm{sat}}\right)^{2}\left[\phi_{\mathrm{B}}^{\mathrm{o}}\left(\Delta \bar{G}_{\mathrm{A}}^{\mathrm{fh}}\right)_{\mathrm{B}}^{*}+\phi_{\mathrm{C}}^{\mathrm{o}}\left(\Delta \bar{G}_{\mathrm{A}}^{\mathrm{fh}}\right)_{\mathrm{C}}^{*}-\right. \\
\left.\bar{V}_{\mathrm{A}}\left(X_{\mathrm{B}}^{\mathrm{o}} \bar{V}_{\mathrm{B}}+X_{\mathrm{C}}^{\mathrm{o}} \bar{V}_{\mathrm{C}}\right)^{-1} \Delta \bar{G}_{\mathrm{BC}}^{\mathrm{fh}}\right]
\end{gathered}
$$

where $a_{A}^{\text {solid }}$ is the activity of the solid solute (defined as the ratio of the fugacity of the solid to the fugacity of the pure subcooled liquid), $\phi_{\mathrm{A}}^{\text {sat }}$ is the overall volume fraction solubility, $\bar{V}$ is the molar volume of the component (designated by subscript), and $X_{\mathrm{B}}^{\mathrm{o}}$ and $X_{\mathrm{C}}^{\mathrm{o}}$ are the mole fraction compositions of the solvent mixture (calculated as if the solute were not present). The overall volume fraction solubility, $\phi_{\mathrm{A}}^{\text {sat }}$, is related to the solubility of the uncomplexed solute and the equilibrium constant by

$$
\phi_{\mathrm{A}}^{\mathrm{sat}}=\phi_{\mathrm{A}_{1}}^{\mathrm{sat}}\left[1+\bar{V}_{\mathrm{A}} K_{\mathrm{AC}}^{\phi} \phi_{\mathrm{C}_{1}} /\left(\bar{V}_{\mathrm{A}}+\bar{V}_{\mathrm{C}}\right)\right]
$$

The quantities $\left(\Delta \bar{G}_{\mathrm{A}}^{\mathrm{fh}}\right)_{\mathrm{B}}^{*}$ and $\left(\Delta \bar{G}_{\mathrm{A}}^{\mathrm{fh}}\right)_{\mathrm{C}}^{*}$ are calculated from the appropriate binary reduction of eq 3 ,

$$
\begin{aligned}
& \left(\Delta \bar{G}_{\mathrm{A}}^{\mathrm{fh}}\right)_{\mathrm{B}}^{*}=\left(1-\phi_{\mathrm{A}}^{\mathrm{sat}}\right)^{-2} R T\left[\ln \left(\mathrm{a}_{\mathrm{A}}^{\mathrm{solid}} / \phi_{\mathrm{A}}^{\mathrm{sat}}\right)-\right. \\
& \left.\left(1-\phi_{\mathrm{A}}^{\mathrm{sat}}\right)\left(1-\frac{\bar{V}_{\mathrm{A}}}{\bar{V}_{\mathrm{B}}}\right)\right] \\
& \left(\Delta \bar{G}_{\mathrm{A}}^{\mathrm{fh}}\right)_{\mathrm{C}}^{*}=\left(1-\phi_{\mathrm{A}}^{\mathrm{sat}}\right)^{-2} R T\left[\ln \left(\mathrm{a}_{\mathrm{A}}^{\mathrm{solid}} / \phi_{\mathrm{A}_{1}}^{\mathrm{sat}}\right)-\right. \\
& \left.1+\bar{V}_{\mathrm{A}}\left(\frac{\phi_{\mathrm{A}_{1}}^{\mathrm{sat}}}{\bar{V}_{\mathrm{A}}}+\frac{\phi_{\mathrm{C}}}{\bar{V}_{\mathrm{C}}}\right)\right]
\end{aligned}
$$

using the molar volumes of the pure components, $\bar{V}_{\mathrm{i}}$, and the solubilities in the pure solvents. The superscript (o) denotes that the solvent compositions are calculated as if the solute were not present.

Postulating the formation of a 1:1 anthracene:benzene complex, the authors demonstrated that eq 3 could describe the solubility of anthracene in benzene plus $n$-heptane and benzene plus isooctane mixtures to within a maximum deviation of $4 \%$ using a single value of $K_{\mathrm{AC}}^{\phi}=1.91$. More importantly, it was noted that the determination of solutesolvent equilibrium constants from solubility measurements does depend on the manner in which nonspecific interactions are incorporated into the model. In the case of anthracene solubilities, failure to include nonspecific interactions led to a calculated value of $K_{\mathrm{AC}}^{\phi}=4.07$ for the anthracene:benzene complex in solvent mixtures containing $n$-heptane.

A subsequent study by McCargar and Acree ${ }^{12}$ compared numerical values for the carbazole-dibutyl ether association constant calculated from measured carbazole solubilities in seven binary dibutyl ether plus alkane solvent mixtures. A simple stoichiometric complexation model based entirely on specific solute-solvent interactions required two equilibrium constants to mathematically describe the experimental solubilities. Calculated equilibrium constants in cyclooctane cosolvent were significantly different from values for the isooctane cosolvent system. In comparison, eq 3 , derived from the NIBS model, described the solubility data to within an average absolute deviation of $2 \%$ using a single carbazoledibutyl ether association constant, which varied from $K_{\mathrm{AC}}^{\phi}=$ 22 for $n$-heptane to $K_{\mathrm{AC}}^{\phi}=30$ for isooctane.

Calculation of nearly identical numerical values for the 
carbazole-dibutyl ether association constant is impressive. Readers should be aware, however, that the seven inert cosolvents studied were of comparable molar volumes ranging from $\bar{V}_{\mathrm{i}}=109 \mathrm{~cm}^{3} / \mathrm{mol}$ for cyclohexane to $\bar{V}_{\mathrm{i}}=166$ $\mathrm{cm}^{3} / \mathrm{mol}$ for isooctane. Equation 3 still needs to be tested with systems having greater cosolvent size disparity. For this reason, we have measured carbazole solubilities in binary dibutyl ether plus $n$-hexadecane and dibutyl ether plus squalane mixtures. Hexadecane and squalane are saturated hydrocarbons having molar volumes of 294 and $525 \mathrm{~cm}^{3} / \mathrm{mol}$, respectively. Results of these measurements, combined with $\Delta \bar{G}_{\mathrm{BC}}^{\mathrm{th}}$ values estimated from anthracene solubilities, should provide a further indication of the application and limitations of eq 3.

Table I-Solubility of Anthracene and Carbazole in Binary Squalane Plus Dibutyl Ether and $\boldsymbol{n}$-Hexadecane Plus Dibutyl Ether Mixtures ${ }^{a}$

Solvent (B) + Solvent $(C) \quad X_{C}^{\circ} \quad X_{A}^{\text {sat }}$

$$
\text { Solute }=\text { Anthracene }
$$

$\begin{array}{ccc}\text { Squalane + Dibutyl Ether } & 0.0000 & 0.00472 \\ 0.1589 & 0.00439 \\ 0.2667 & 0.00424 \\ 0.4445 & 0.00396 \\ 0.5711 & 0.00385 \\ 0.6675 & 0.00375 \\ 0.7560 & 0.00368 \\ 0.8169 & 0.00366 \\ 0.9019 & 0.00361 \\ 1.0000 & 0.00354 \\ n \text {-Hexadecane + Dibutyl Ether } & 0.0000 & 0.00380 \\ & 0.1328 & 0.00376 \\ & 0.2139 & 0.00372 \\ & 0.3046 & 0.00370 \\ 0.3963 & 0.00370 \\ & 0.4844 & 0.00368 \\ 0.5811 & 0.00367 \\ 0.7051 & 0.00368 \\ & 0.7993 & 0.00365 \\ & 0.8887 & 0.00360 \\ 1.0000 & 0.00354\end{array}$

\section{Solute $=$ Carbazole}

\begin{tabular}{cll} 
Squalane + Dibutyl Ether & 0.0000 & 0.000671 \\
0.1604 & 0.00107 \\
0.1664 & 0.00108 \\
0.2687 & 0.00132 \\
0.4471 & 0.00185 \\
0.5693 & 0.00234 \\
0.5757 & 0.00241 \\
0.6726 & 0.00274 \\
0.7784 & 0.00321 \\
0.8289 & 0.00356 \\
0.9030 & 0.00413 \\
0.9625 & 0.00470 \\
1.0000 & 0.00501 \\
$n$-Hexadecane + Dibutyl Ether & 0.0000 & 0.000414 \\
& 0.1380 & 0.000807 \\
0.2098 & 0.00102 \\
0.3130 & 0.00136 \\
& 0.4032 & 0.00168 \\
0.4774 & 0.00202 \\
0.5818 & 0.00237 \\
0.7127 & 0.00308 \\
& 0.8009 & 0.00371 \\
0.9146 & 0.00430 \\
1.0000 & 0.00501 \\
\hline
\end{tabular}

${ }^{a}$ Determined at $25^{\circ} \mathrm{C}$.

\section{Experimental Section}

Carbazole (Aldrich; 99\%) was recrystallized several times from absolute ethanol, giving a melting point of $246.5+0.5{ }^{\circ} \mathrm{C}$ (lit. value ${ }^{14}$ 247-248 ${ }^{\circ} \mathrm{C}$ ). Dibutyl ether (Aldrich; Gold Label) was stored over molecular sieves shortly before use to remove trace amounts of water. Anthracene (Aldrich; Gold Label), squalane (Aldrich; 99\%), and $n$-hexadecane (Aldrich; 99\%) were used as received. Squalane is a fairly viscous, high boiling point liquid, and is difficult to purify. ${ }^{15,16}$ To minimize the effect that minor impurities may have on the calculated association constants, sufficient quantities of squalane and $n$-hexadecane were purchased so that all solvent mixtures in a system could be prepared from the same bottle. Preparation of the binary mixtures in this manner insured that the ratio of any impurity to hydrocarbon cosolvent was maintained constant. Binary solvent mixtures were prepared by weight, enabling compositions to be calculated to $0.0001 \mathrm{~mol}$ fraction.

Excess solute and solvent were placed in amber glass bottles and allowed to equilibrate in a constant temperature bath at $25.0 \pm$ $0.1{ }^{\circ} \mathrm{C}$ for several days. The attainment of equilibrium was verified by repetitive measurements after several additional days and, in some cases, by approaching equilibrium from supersaturation by pre-equilibrating the solution at a higher temperature. Aliquots of saturated solutions were transferred through a coarse filter into a tared volumetric flask, to determine the amount of sample, and then diluted quantitatively with carbon tetrachloride. Concentrations were determined spectrophotometrically on a Bausch and Lomb Spectronic 2000. Experimental solubilities of anthracene and carbazole in binary solvent mixtures of dibutyl ether with squalane and $n$ hexadecane are listed in Table I. Numerical values represent the average of between four and eight independent determinations, with the measurements being reproducible to within $\pm 2 \%$.

\section{Results and Discussion}

Despite the complex appearance of eq 3 , its predictive application is relatively straightforward, and it is similar in concept to the numerical example presented in an earlier paper $^{7}$ for systems containing only nonspecific interactions. The quantities $\left(\Delta \bar{G}_{\mathrm{A}}^{\mathrm{fh}}\right)_{\mathrm{B}}^{*}$ and $\left(\Delta \bar{G}_{\mathrm{A}}^{\mathrm{fh}}\right)_{\mathrm{C}}^{*}$ are calculated from the volume fraction solubility of the solid in the pure solvents using an assumed value for the equilibrium constant. These quantities, along with the excess Gibbs free energy of the binary solvent mixture (usually obtained from the literature), are then used in eq 3 to calculate $\phi_{\mathrm{A}_{1}}^{\text {sat }}$ via a reiterative approach. The entire procedure can be repeated until one obtains the numerical value of $K_{\mathrm{AC}}^{\phi}$ which best describes the experimental solubility in a particular binary solvent mixture.

When the solubility is sufficiently small, $\phi_{\mathrm{A}}^{\mathrm{sat}}=0$ and $1-$ $\phi_{\mathrm{A}}^{\text {sat }}=1$, very reasonable estimates of $K_{\mathrm{AC}}^{\phi}$ are often obtainable from a simplified form of eq 3 relating the overall solute solubility in the binary solvent mixture to the solubility in the two pure solvents, and $\left(\phi_{\mathrm{A}}^{\text {sat }}\right)_{\mathrm{C}}$ :

$$
\begin{gathered}
\ln \phi_{\mathrm{A}}^{\mathrm{sat}}=\phi_{\mathrm{B}}^{\mathrm{o}} \ln \left(\phi_{\mathrm{A}}^{\mathrm{sat}}\right)_{\mathrm{B}}+\phi_{\mathrm{C}}^{\mathrm{o}} \ln \left(\phi_{\mathrm{A}}^{\mathrm{sat}}\right)_{\mathrm{C}}+ \\
\ln \left[1+\bar{V}_{\mathrm{A}} K_{\mathrm{AC}}^{\phi} \phi_{\mathrm{C}}^{\mathrm{o}} /\left(\bar{V}_{\mathrm{A}}+\bar{V}_{\mathrm{C}}\right)\right]- \\
\phi_{\mathrm{C}}^{\mathrm{o}} \ln \left[1+\bar{V}_{\mathrm{A}} K_{\mathrm{AC}}^{\phi} /\left(\bar{V}_{\mathrm{A}}+\bar{V}_{\mathrm{C}}\right)\right]+ \\
\frac{\bar{V}_{\mathrm{A}} \Delta \bar{G}_{\mathrm{BC}}^{\mathrm{fh}}}{R T\left(X_{\mathrm{B}}^{\mathrm{o}} \bar{V}_{\mathrm{B}}+X_{\mathrm{C}}^{\mathrm{o}} \bar{V}_{\mathrm{C}}\right)}
\end{gathered}
$$

To calculate the equilibrium constant, one substitutes the 
solute solubility at a particular solvent composition (e.g., $\phi_{\mathrm{C}}^{\circ}$ $=0.5$ ) into eq 7 and solves the resulting mathematical expression for $K_{\mathrm{AC}}^{\phi}$. For example, if one wished to evaluate the carbazole-dibutyl ether association constant from the solubility in the dibutyl ether plus $n$-hexadecane system at $X_{\mathrm{C}}^{\circ}=0.5818\left(\phi_{\mathrm{C}}^{\circ}=0.4463\right)$, one solves eq 7 using the values of $\left(\phi_{\mathrm{A}}^{\mathrm{sat}}\right)_{\mathrm{C}}=0.004414,\left(\phi_{\mathrm{A}}^{\mathrm{sat}}\right)_{\mathrm{B}}=0.000211$, and $\phi_{\mathrm{A}}^{\mathrm{sat}}=0.001602$ (based on the ideal molar volume approximation), and $\Delta \bar{G}_{\mathrm{BC}}^{\mathrm{fh}}$ $=24.8 \mathrm{cal} / \mathrm{mol}$ (estimated from the solubility parameter approach):

$$
\begin{gathered}
\Delta \bar{G}_{\mathrm{BC}}^{\mathrm{ex}}=\phi_{\mathrm{B}}^{\mathrm{o}} \phi_{\mathrm{C}}^{\mathrm{o}}\left(X_{\mathrm{B}}^{\mathrm{o}} \bar{V}_{\mathrm{B}}+X_{\mathrm{C}}^{\mathrm{o}} \bar{V}_{\mathrm{C}}\right)\left(\delta_{\mathrm{B}}-\delta_{\mathrm{C}}\right)^{2} \\
\Delta \bar{G}_{\mathrm{BC}}^{\mathrm{fh}}=R T\left[\ln \left(X_{\mathrm{B}}^{\mathrm{o}} \bar{V}_{\mathrm{B}}+X_{\mathrm{C}}^{\mathrm{o}} \bar{V}_{\mathrm{C}}\right)-X_{\mathrm{B}}^{\mathrm{o}} \ln \bar{V}_{\mathrm{B}}-\right. \\
\left.X_{\mathrm{C}}^{\mathrm{o}} \ln \bar{V}_{\mathrm{C}}\right]+\Delta \bar{G}_{\mathrm{BC}}^{\mathrm{ex}}
\end{gathered}
$$

where $\delta$ represents the solubility parameter. The calculated value of the association constant is $\left(K_{\mathrm{AC}}^{\phi}\right)$ is 22.1 , which differs slightly from an "optimized" $K_{\mathrm{AC}}^{\phi}$ of 24.0 for the $n$ hexadecane cosolvent. The optimized equilibrium constant enabled back calculation of the solubility data to within an average absolute deviation of $1.4 \%$. Deviations of this magnitude are comparable with those noted in earlier papers ${ }^{1,3-7,10.11}$ documenting the ability of the basic NIBS model to predict iodine, naphthalene, benzil, $p$-dibromobenzene, pyrene, benzoic acid, biphenyl, anthracene, stannic iodide, and $p$-benzoquinone in systems containing only nonspecific interactions.

Calculation of the carbazole-dibutyl ether association constant from measured solubilities in binary dibutyl ether plus $n$-hexadecane and dibutyl ether plus squalane mixtures does require a priori knowledge of $\Delta \bar{G}_{\mathrm{BC}}^{\mathrm{h}}$ values for both binary systems. Unfortunately, experimental values are not available in the chemical literature, but must be estimated. Excess Gibbs free energies can be estimated using the solubility parameter approach or can be determined indirectly from experimental solubilities of an inert anthracene solute, assuming that the basic NIBS model $\left(K_{\mathrm{AC}}^{\phi}=0\right)$ perfectly describes the simpler noncomplexing systems. ${ }^{13}$ Two methods for obtaining $\Delta \bar{G}_{\mathrm{BC}}^{\mathrm{fh}}$ values are considered because the solubility parameter approach may not be truly applicable to binary mixtures of such large molecular size disparity. Chiou and Manes ${ }^{17.18}$ recently showed that the Flory-Huggins model, and not Raoult's law, provided the better thermodynamic description of nonelectrolyte solutions

Table II-Association Constant for Presumed Carbazole-Dibutyl Ether Complex Calculated from the Extended NIBS Model

\begin{tabular}{lcc}
\hline Inert Cosolvent & $K_{\mathrm{AC}}^{b}$ & Deviation, $\%^{a}$ \\
\hline$n$-Hexadecane & $24.0^{b}$ & 1.4 \\
Squalane & $24.6^{c}$ & 1.4 \\
& $23.0^{b}$ & 1.7 \\
$n$-Heptane & $25.0^{c}$ & 1.8 \\
$n$-Octane & $22.0^{d}$ & 1.8 \\
\hline
\end{tabular}

${ }^{a}$ Deviation $(\%)=(100 / N) \sum\left|\ln \left(X_{A}^{\text {calc }} / X_{A}^{\exp }\right)\right| .{ }^{b}$ Binary solvent $\Delta \bar{G}_{B C}^{\text {th }}$ values approximated via Scatchard-Hildebrand solubility parameter approach; properties used in calculations include solubility parameters $\delta_{i}=7.99,7.90$, and $7.76 \mathrm{cal}^{1.2} \mathrm{~cm}^{-3.2}$, and molar volumes $\bar{\nabla}_{i}=294.12$, 525.30 , and $170.41 \mathrm{~cm}^{3} / \mathrm{mol}$ for $n$-hexadecane, squalane, and dibutyl ether, respectively. ${ }^{C}$ Binary solvent $\Delta \bar{G}_{\mathrm{BC}}^{\text {th }}$ values estimated from measured anthracene solubilities given in Table I. ${ }^{d}$ Values taken from ref 12. where the molar volumes of the components differed by a factor of $\sim 3.9$ or more. The solubility parameter approach is based on deviations being relative to Raoult's law. Furthermore, the published solubility parameter for squalane, $\delta_{i}=$ $6.2 \mathrm{cal}^{1 / 2} \mathrm{~cm}^{-3 / 2},{ }^{19}$ seems much too small compared with an approximation of $\delta_{i}=7.90 \mathrm{cal}^{1 / 2} \mathrm{~cm}^{-3 / 2}$ that is based on Fedor's group contribution method..$^{20.21}$ The latter value was believed to be more realistic and was used in computations of $\Delta \bar{G}_{\mathrm{BC}}^{\mathrm{fh}}$

Large errors in binary solvent excess Gibbs free energies can have a significant effect on the calculated value of $K_{\mathrm{AC}}^{\phi}$. For the systems considered in this study, large molar volumes for the hydrocarbon cosolvents, relative to that of the carbazole solute, diminish contributions from the $\bar{V}_{\mathrm{A}} \Delta \bar{G}_{\mathrm{BC}}^{\mathrm{fh}} /\left(X_{\mathrm{B}}^{\mathrm{o}} \bar{V}_{\mathrm{B}}+X_{\mathrm{C}}^{\mathrm{o}} \bar{V}_{\mathrm{C}}\right) R T$ unmixing term. As shown in Table II, $K_{\mathrm{AC}}^{\phi}$ values depend only slightly on whether $\Delta \bar{G}_{\mathrm{BC}}^{\mathrm{fh}}$ is estimated via the solubility parameter model or measured anthracene solubilities. Irrespective of the method used to estimate $\Delta \bar{G}_{\mathrm{BC}}^{\mathrm{fh}}$, the calculated carbazole-dibutyl ether association constants fall between values reported previously. The fact that the extended NIBS model gives nearly identical values of $K_{\mathrm{AC}}^{\phi}$ for nine inert hydrocarbon cosolvents, covering approximately a fivefold range in molar volumes, further establishes its applicability to associated solutions.

\section{References and Notes}

1. Acree, W. E., Jr.; Bertrand, G. L. J. Phys. Chem. 1977, 81, 11701173.

2. Acree, W. E., Jr.; Bertrand, G. L. J. Phys. Chem. 1979, 83, 23552358.

3. Acree, W. E., Jr.; Bertrand, G. L. J. Pharm. Sci. 1981, 70, 10331036.

4. Acree, W. E., Jr.; Bertrand, G. L. J. Solution Chem. 1983, 12, 101-113.

5. Acree, W. E., Jr.; Rytting, J. H. J. Pharm. Sci. 1982, 71, 201205.

6. Acree, W. E., Jr.; Rytting, J. H. Int. J. Pharm. 1982, 10, 231238.

7. Acree, W. E., Jr.; Rytting, J. H. J. Pharm. Sci. 1983, 72, 292 296.

8. Acree, W. E., Jr.; McHan, D. R.; Rytting, J. H. J. Pharm. Sci. $1983,72,929-934$.

9. Acree, W. E., Jr. Int. J. Pharm. 1983, 15, 159-165.

10. Judy, C. L.; Pontikos, N. M.; Acree, W. E., Jr. J. Chem. Eng. Data 1987, 32, 60-62.

11. Judy, C. L.; Pontikos, N. M.; Acree, W. E., Jr. Phys. Chem. Liq. 1987, 16, 179-187.

12. McCargar, J. W.; Acree, W. E., Jr., submitted for publication in Phys. Chem. Liq.

13. Procyk, A. D.; Bissell, M.; Street, K. W., Jr.; Acree, W. E., Jr., submitted for publication in $J$. Pharm. Sci.

14. CRC Handbook of Chemistry and Physics, 66 th Ed; Weast, R. C., Ed.; CRC: Boca Raton, FL, 1985.

15. Chien, J. C. W. J. Phys. Chem. 1967, 71, 2247-2252.

16. Urone, P.; Takahashi, Y.; Kennedy, G. J.Phys. Chem. 1970, 74, 2326-2333.

17. Chiou, C. T.; Manes, M. J. Chem. Soc., Faraday Trans. 1 1986, 82, 243-246.

18. Chiou, C. T. Environ. Sci. Technol. 1985, 19, 57-62. 19. Sewell, P. A.; Stock, R. Trans. Faraday Soc. 1971, 67, 1617-
1625.

20. Fedors, R. F. Polym. Eng. Sci. 1974, 14, 147-154.

21. Barton, A. F. M. CRC Handbook of Solubility Parameters and Other Cohesion Parameters, CRC: Boca Raton, FL, 1983; pp 6466.

\section{Acknowledgments}

Acknowledgment is made to the Donors of the Petroleum Research Fund, administered by the American Chemical Society, for partial support of this research. 